Linguistic Issues in Language Technology - LiLT Submitted, October 2015

\title{
A computational analysis of poetic style
}

Imagism and its influence on modern professional and amateur poetry

Justine T. Kao

Dan Jurafsky 



\title{
A computational analysis of poetic style
}

\section{Imagism and its influence on modern professional and amateur poetry}

Justine T. KaO, Department of Psychology, Stanford University, justinek@stanford.edu

Dan JuRAFSKY, Department of Linguistics, Stanford University, jurafsky@stanford.edu

\begin{abstract}
How do standards of poetic beauty change as a function of time and expertise? Here we use computational methods to compare the stylistic features of 359 English poems written by 19th century professional poets, Imagist poets, contemporary professional poets, and contemporary amateur poets. Building upon techniques designed to analyze style and sentiment in texts, we examine elements of poetic craft such as imagery, sound devices, emotive language, and diction. We find that contemporary professional poets use significantly more concrete words than 19th century poets, fewer emotional words, and more complex sound devices. These changes are consistent with the tenets of Imagism, an early 20thcentury literary movement. Further analyses show that contemporary amateur poems resemble 19th century professional poems more than contemporary professional poems on several dimensions. The stylistic similarities between contemporary amateur poems and 19th century professional poems suggest that elite standards of poetic beauty in the past "trickled down" to influence amateur works in the present. Our
\end{abstract}

LiLT Volume 12, Issue 3, October 2015.

A computational analysis of poetic style.

Copyright (C) 2015, CSLI Publications. 
results highlight the influence of Imagism on the modern aesthetic and reveal the dynamics between "high" and "low" art. We suggest that computational linguistics may shed light on the forces and trends that shape poetic style. 


\section{Introduction}

From Homer's epics to Li Po's elegant verses to Billy Collins' startlingly insightful portrayals of ordinary moments in life, poetry has been widely celebrated across languages, cultures, and time. Countless readers have experienced the power of a beautiful poem; however, an astute reader will notice that this power takes a different form in Shakespeare's measured sonnets than it does in Pablo Neruda's lush poetry. In this paper, we are interested in the forces and elements that shape the aesthetic standards of poetry. In particular, how do literary movements transform ideals of poetic beauty? How do changes in aesthetic standards impact poets with high versus low levels of expertise? Can we characterize literary movements using precise quantitative methods and analyze their influence on a large scale?

Many literary critics, historians, and social scientists have studied artistic change and proposed theories about its inception and development. These scholars have approached artistic change from the perspective of direct influence among artists (Clayton and Rothstein, 1991, Levenson, 1986), legitimation of new or previously ignored art forms due to social movements (Baumann, 2007, Isaac, 2009), and the dynamics between high and low social classes (Simmel 1957). This diversity of approaches suggests that a holistic view of artistic change should incorporate the influence of individual artists as well as broader societal forces. While the ideas proposed in these works are enlightening and influential, their methods have been mostly qualitative, making it difficult to draw objective and data-driven conclusions about large bodies of texts.

Martindale (1990) was one of the first scholars to use quantitative methods to comprehensively analyze a sizable collection of artwork across several time periods. His analysis showed that visual, verbal, and musical art all tend to exhibit higher complexity over time, suggesting that a major force for artistic change may be the pressure to be less predictable and thus more complex. While this research presents compelling quantitative evidence to support a theory of artistic change, it (largely intentionally) ignores the historical context in which change takes place. Furthermore, Martindale regards certain types of art such as poetry as a product of the elite and overlooks poetry generated and consumed by the masses. While this approach sheds light on broad patterns of artistic change, it fails to consider the different ways in which the force of change acts upon artists in different historical and social contexts.

In this paper, we apply the same degree of quantitative rigor to ex- 
amine changes surrounding a specific literary movement in the English language: Imagism. By focusing on a particular movement, we are able to examine whether and how powerful literary leaders can dramatically shift the standards of poetic beauty within a short amount of time. Furthermore, by comparing the movement's effect on elite poets and amateur poets, we aim to explore the differences between high and low art as well as their responsiveness to change.

We chose to focus on the Imagist movement for two reasons. First, Imagism is regarded by many literary critics as "the beginning of modern literature in English" (Pratt, 1992). Leaders of the Imagism movement articulated and championed some of the principles of craft still taught in creative writing workshops today, such as the advice to show and not tell (Addonizio and Laux, 1997, Burroway, 2007). If the Imagism movement truly had a strong influence on modern aesthetic standards, then we should find significant differences between the styles of poems written prior to and following the movement 1 Second, while the work of amateur poets before the 21st century is mostly undocumented, the Internet now enables easy dissemination and documentation of poems produced by the masses. It is now possible to collect poems not only from modern anthologized poets, but also from modern amateur poets who published their work on the Internet. By choosing a movement closer to our times, we are able to compare the influence of Imagism on poems written by poets with vastly different levels of skill and formal training.

\section{The Imagist movement}

Given its significance, the Imagism movement was surprisingly small and short-lived. The movement officially launched in 1912 and ended in 1917, involving only a handful of English and American poets, including Ezra Pound, Amy Lowell, William Carlos Williams, and James Joyce. Ezra Pound is regarded as the intellectual leader of the movement (although Amy Lowell took over soon afterwards, not without some drama). Although there is speculation about Pound's personal motives for launching the movement (Thacker, 2011), Imagism is often construed as a reaction against Georgian and Victorian styles, which are characterized by abstract and sentimental language (Frank, 1991).

\footnotetext{
${ }^{1}$ We note that other literary movements that overlap in time with Imagism make it difficult to draw definitive conclusions about whether Imagism is solely responsible for the changes during this period. However, our main goal is to provide quantitative evidence that such differences exist and to track these differences across time and expertise. We leave it to future work to more carefully disentangle the causal mechanisms that engendered such changes.
} 
The Imagists articulated their aesthetic ideals in an anthology published in 1915, titled Some Imagist Poets (Lowell, 1915). Here we list the six tenets they proposed, modified for brevity:

1. To use the language of common speech, but to employ always the exact word, not the nearly-exact, nor the merely decorative word.

2. To create new rhythms - as the expression of new moods - and not to copy old rhythms, which merely echo old moods.

3. To allow absolute freedom in the choice of subject.

4. To present an image. We believe that poetry should render particulars exactly and not deal in vague generalities.

5. To produce poetry that is hard and clear, never blurred nor indefinite.

6. Finally, concentration is of the very essence of poetry.

Pound's poem titled In a Station of the Metro, published in Poetry magazine in 1913, embodies the central tenets of the Imagism movement:

The apparition of these faces in the crowd;

Petals on a wet, black bough.

In fourteen words, the poem constructs a clear and compelling image that conveys an abstract emotional experience without explicitly describing it. The poem does not follow a strict meter or rhyme scheme; instead, the relationship between the two lines is one of imagery rather than one of sound. The image of faces in the crowd is equated with an image of petals on a bough, remnants of flowers that had just been separated from the tree after rain. A sense of ephemerality is evoked by the precise and concrete image of these delicate petals, which lingers in the reader's mind for much longer than an abstract statement about the transience of life.

According to Imagists, the work of a great poet is to select the right image that causes the reader to experience a particular emotion or infer a particular reality (Hamilton, 2004). As Pound said, "The gulf between evocation and description is the unbridgeable difference between genius and talent." Regardless of whether the aesthetic ideals of Imagism provide an objective measure of "genius," the question of whether Imagists were successful at shifting standards of poetic beauty and influencing modern poets to adopt these ideals is the one we wish to investigate. 


\section{Features of Imagism}

The tenets articulated in the Imagist manifesto form the basis of our analysis. In order to determine the degree to which a particular poem conforms to Imagist ideals, we first define specific features that correlate with each of these tenets. We then measure the number of times a poem uses these features. By comparing these features across different sets of poems, we can identify the amount of Imagism's influence on poets from different time periods and with varying levels of expertise. Here we motivate and describe the set of features selected for this purpose.

\subsection{Concrete imagery}

Imagists put great emphasis on depicting concrete, specific objects and avoiding abstractions and generalizations (Aldington et al., 1916). We quantified the degree of concreteness in poems using the following predefined lexicons and psycholinguistic measures.

The Harvard General Inquirer (Stone et al., 1966) consists of 182 word categories, including a category for words referring to concrete objects (Object: 661 words) and one for words referring to abstract concepts (ABS: 276 words). We computed an Object score for each poem by counting the number of words that appear in the Object category and dividing it by the total number of words in the poem. We similarly computed an Abstract score by counting the number of words that appear in the ABS category and dividing it by poem length.

For more fine-grained psycholinguistic measures of imageability, we used the MRC Psycholinguistic Database (Wilson, 1988), which contains imageability ratings for 4, 954 words (Coltheart, 1981). We derived an Imageability score for each poem by computing the average imageability rating for all of the words in the poem that appeared in the database. Finally, we used concreteness ratings for 39, 955 words collected by Brysbaert et al. (2013) to compute the average concreteness of all words in the poem, resulting in a Concreteness score.

\subsection{Emotional language}

As seen in Pound's In a Station of the Metro, Imagist poets often use carefully chosen objects and imagery to evoke emotional reactions instead of depicting emotions explicitly (Hamilton, 2004). To quantify the degree of emotion explicitly described in each poem, we used the EMOT category (311 words) in the Harvard General Inquirer (Stone et al., 1966). We computed an Emotion score for each poem by counting and normalizing the number of words that appear in the EMOT category.

To account for more fine-grained differences between negative- 
valence and positive-valence words (e.g. "torture" v.s. "love") and lowarousal and high-arousal words (e.g. "sad" v.s. "panicky"), we in addition used the valence and arousal norms of 13,915 words collected by Warriner et al. (2013). A Valence score was obtained for each poem by computing the average valence rating for all words in the poem that appeared in the database, and an Arousal score from average arousal ratings.

\subsection{Sound devices}

To examine the types of sound devices used in different poems, we computed sound device features using Kaplan (2006)'s PoetryAnalyzer, which utilizes the Carnegie Mellon Pronouncing Dictionary to identify phonetic patterns indicative of poetic sound devices. We examined six different sound devices, which are listed as major elements of poetic craft in influential handbooks on creative writing (Burroway, 2007, Addonizio and Laux, 1997): identity rhyme, perfect rhyme, slant rhyme, alliteration, consonance, and assonance.

The PoetryAnalyzer identifies rhymes by examining phoneme sequences at the end of lines. If two words in a window of four line endings have identical phoneme sequences, then an instance of an identity rhyme is recorded. The final count of identity end rhymes is divided by the total number of words in the poem to produce an IdentityEndRhyme score. If two words in the window have different initial consonants but identical phoneme sequences from the stressed vowel phoneme onward, then the count for perfect end rhymes is incremented, and the final count normalized by poem length to produce a PerfectEndRhyme score. If two words in the window of four line endings have the same stressed vowel but different phonemes following the stressed vowel, then the count for slant end rhymes is incremented, and the final count normalized to produce a SlantEndRhyme score. If the initial phoneme of two consecutive words are identical consonants, an alliteration count is incremented, and the final count normalized to obtain an Alliteration score. If there are at least two identical consonant phonemes in a window of nine syllables, the consonance count is incremented, and the final count similarly normalized to obtain a Consonance score. Finally, if there are at least two identical vowel phonemes in a window of nine syllables, the assonance count is incremented, and the final count normalized to obtain an Assonance score.

\subsection{Diction}

The first tenet of Imagism is "to use the language of common speech, but always the exact word, not the nearly-exact, not the merely decorative 
word" (Aldington et al., 1916). This suggests that diction, or word choice, may reveal interesting characteristics of Imagism.

We measured the "commonness" of language used in a poem by computing average word length (WordLength) and average word frequency (WordFreq), which are often used as proxies for word difficulty (Breland, 1996). We measured average word length by computing the average length of words in each poem, in units of letters. This was done by summing up the number of letters in a poem and dividing the total by the number of words in the poem. We measured average word frequencies using a list of the top 500,000 most frequent words in the Corpus of Contemporary American English (COCA) (Davies, 2011). For each poem, we summed up the word frequencies of every word and divided the total by the number of words in the poem to obtain a WordFreq score.

Finally, to measure the "exactness" of language, we assumed that more precise words tend to be appropriate for fewer contexts. According to this logic, "exactness" can be approximated by the ratio of total word types to total number of words in each poem, known as the type-token ratio. Poems with higher type-token ratios avoid repeating the same words and are assumed to employ more diverse and precise vocabulary (Ben-Simon and Bennett, 2007, Pitler, E. and Nenkova, Ani, 2008). We summed up the number of unique word types in a poem and divided the sum by the total number of word instances in the poem to compute a TypeTokenRatio score. Table 1 provides a summary of all 16 features and their corresponding examples.

\section{Study 1: Imagists vs. 19th century professional poets}

We first validated the 16 features described above by testing whether poems written by Imagist poets differ significantly from poems written by other poets in the 19th century along these feature dimensions.

\subsection{Materials and methods}

To construct a dataset of Imagist poetry, we compiled poems from two seminal anthologies that put forth the ideals of Imagism: Des Imagistes (Pound, 1914), which included 34 poems written in English, and the first anthology in the series Some Imagist Poets (Lowell, 1915), which included 37 poems in English. This resulted in a total of 71 Imagist poems, ranging from 17 to 1039 words in length with an average length of 163.48 words (see Appendix for the full list of poets and poems).

For our comparison dataset, we collected English poems written by 19 th century American poets, defined as American poets born between 1801 and 1900, from a website called "Famous Poets and Poems" 


\begin{tabular}{ll} 
Feature & Examples \\
\hline Object & boat; leaf \\
Abstract & day; love \\
Imageability & an $\rightarrow$ beach \\
Concreteness & although $\rightarrow$ comb \\
\hline Emotion & confidence; anxious \\
Valence & torture $\rightarrow$ love \\
Arousal & sad $\rightarrow$ panicky \\
\hline Identity end rhyme & restore / store \\
Perfect end rhyme & floor / store \\
Slant end rhyme & bred / end \\
Alliteration & frozen field \\
Consonance & brown skin hung \\
Assonance & shallower and yellowed \\
\hline Word length & - \\
Word frequency & - \\
Type-token ratio & - \\
\hline
\end{tabular}

TABLE 1 Summary of features

(http://famouspoetsandpoems.com). To ensure that we select prolific poets whose works are well known, we selected forty-four poets with more than ten poems listed on the website. None of the poets selected were involved in the Imagist movement. We then randomly selected one to five poems from each poet, resulting in 88 poems written by 19th century non-imagist poets. These poems ranged from 12 to 1775 words in length, with an average length of 217.35 words (see Appendix for the full list of poets and poems) ${ }^{2}$

\subsection{Results}

We measured the features described in Section 2 for all 159 poems. Figure 1 shows the mean feature scores for poems written by 19th century non-Imagist poets and Imagist poets, while Table 2 indicates whether the differences are statistically significant ${ }^{3}$

Our features for concrete imagery quantify distinctive characteristics of Imagist poems and distinguish them from 19th century poems. Imagist poems contain marginally significantly more Object words

\footnotetext{
${ }^{2}$ As a shorthand, we will refer to poems written by Imagists as Imagist poems, poems written by non-Imagist poets born in the 19th century as 19th century poems, poems written by professional poets born in the 20th century as contemporary poems, and poems written by amateur poets as amateur poems.

${ }^{3}$ Throughout this work, we applied a two-tailed unpaired $t$-test in which we did not assume the variance for the two populations to be equal.
} 


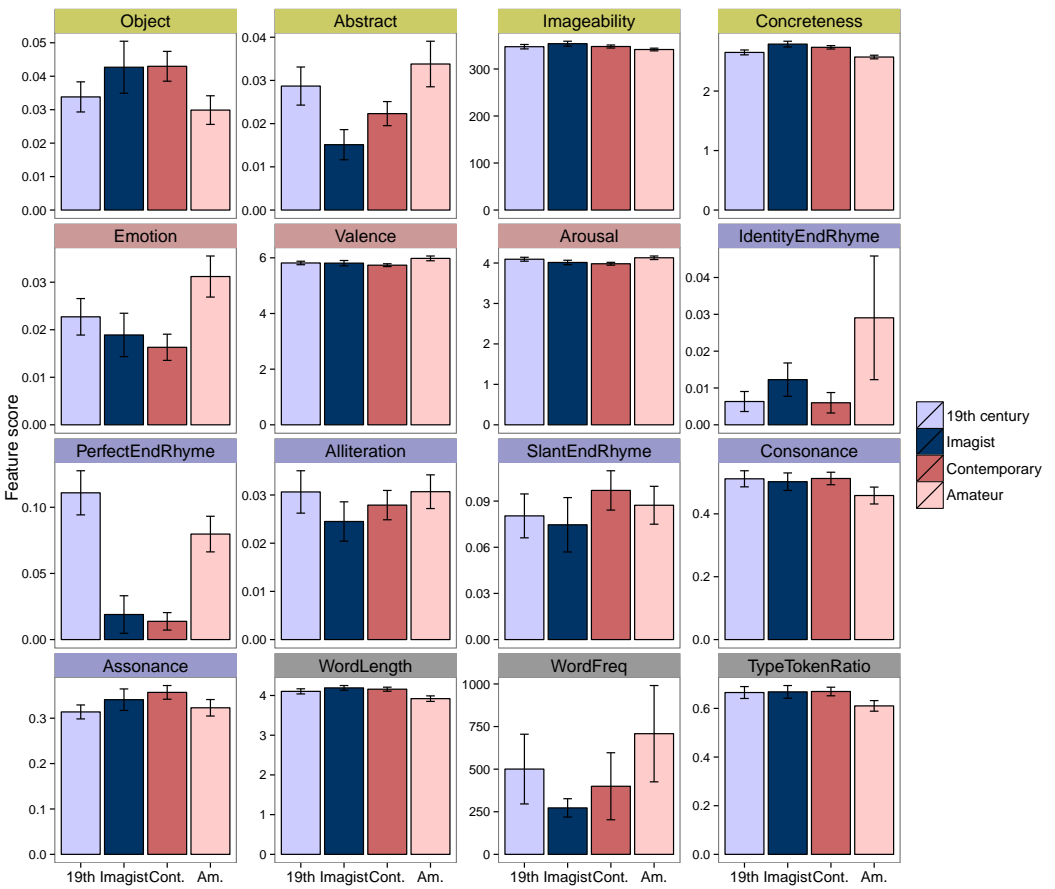

FIGURE 1 Mean feature scores (and 95\% confidence intervals) for poems written by 19 th century poets, Imagist poets, contemporary professional poets, and contemporary amateur poets. 


\begin{tabular}{lrrr}
\hline Feature & 19th $(\mathrm{N}=88)$ & Imagist $(\mathrm{N}=71)$ & Significant? \\
\hline Object & 0.034 & 0.043 & marginal \\
Abstract & 0.029 & 0.015 & yes \\
Imageability & 347.399 & 353.791 & marginal \\
Concreteness & 2.649 & 2.789 & yes \\
\hline Emotion & 0.023 & 0.019 & no \\
Valence & 5.816 & 5.810 & no \\
Arousal & 4.094 & 4.014 & yes \\
\hline IdentityEndRhyme & 0.006 & 0.012 & yes \\
PerfectEndRhyme & 0.111 & 0.019 & yes \\
Alliteration & 0.031 & 0.025 & yes \\
SlantEndRhyme & 0.080 & 0.075 & no \\
Consonance & 0.511 & 0.502 & no \\
Assonance & 0.314 & 0.341 & marginal \\
\hline WordLength & 4.104 & 4.191 & marginal \\
WordFreq & 500.443 & 272.647 & yes \\
TypeTokenRatio & 0.665 & 0.668 & no \\
\hline
\end{tabular}

TABLE 2 Average feature scores for poems written by Imagist poets and 19 th century poets, as well as whether differences between the two groups are statistically significant. 
$(t(114.76)=1.97, p=0.051)$ and significantly fewer Abstract words $(t(154.53)=-4.80, p<0.00001)$. In addition, Imagist poems score marginally significantly higher on Imageability $(t(150.04)=1.80, p=$ $0.07)$, and significantly higher on Concreteness $(t(146.41)=4.38, p<$ $0.000001)$.

In our analysis of emotional language, we found that poems written by Imagists do not contain significantly fewer Emotion words $(t(145.68)=-1.27, p=0.20)$, or differ significantly from 19th century poems in terms of Valence $(t(125.95)=-0.10, p=0.92)$. However, Imagist poems score significantly lower on Arousal $(t(148.96)=$ $-2.17, p=0.03)$, suggesting that Imagist poets use language that demonstrates fewer explicitly strong emotions. While the Emotion and Valence features do not distinguish Imagist poems, ratings of emotional arousal may better capture the impression of Imagism as using imagery to evoke subtle emotions rather than using explicitly emotional language to describe strong emotions.

Besides the use of concrete imagery, perhaps the most distinguishing characteristic of the Imagist style is its departure from traditional rhyme schemes. Consistent with our predictions, Imagist poems contain significantly fewer perfect end rhymes than 19th century poems $(t(156.5)=-8.37, p<0.00001)$. Rather surprisingly, our collection of Imagist poems contains significantly more identity end rhymes $(t(117.59)=2.24, p=0.027)$, perhaps due to the presence of repeated words. Imagist poems contain significantly fewer occurrences of alliteration $(t(158.86)=-2.04, p=0.04)$. However, they contain marginally significantly more occurrences of assonance $(t(124.08)=1.91, p=0.059)$, a subtler sound device than rhyme and alliteration. There were no significant differences in the occurrences of slant end rhymes $(t(142.59)=-0.51, p=0.61)$ and consonance $(t(151.48)=-0.48, p=0.63)$.

Finally, our analysis of diction suggests that, contrary to the tenet promoting the use of "the language of common speech," Imagist poets actually used marginally significantly longer $(t(156.89)=1.97, p=$ $0.051)$ and significantly less frequent $(t(98.82)=-2.14, p=0.035)$ words than other 19th century poets. They also did not use significantly more varied words, as measured by type-token ratio $(t(152.77)=$ $0.15, p=0.88)$. This departure from our prediction highlights an interesting tension within the first tenet of the Imagist manifesto. While the language of common speech is desired, the pressure to employ "the exact word" pushes contemporary poets to choose words with precise meanings, which tend to be words that are less frequently used because their meanings are only appropriate in highly specific contexts. 
Testing the 16 features we designed on a set of poems written by Imagists and their peers, we find that more concrete imagery and fewer perfect end rhymes may be the most distinguishing features of Imagist poetry, as well as more subdued emotional language. While the other features did not consistently reveal interesting differences between Imagist poems and 19th century poems, we will continue using all 16 features in the following studies to observe whether they capture differences between other sets of poems.

\section{Study 2: Contemporary vs. 19th century professional poets}

Imagism is thought to have had a great influence on the style of modern poets. To examine the influence of Imagist ideals on the modern literary aesthetic, in this study we compared poems written by contemporary poets (poets born in the 20th century) to those written by 19th century poets.

\subsection{Materials and methods}

We selected 100 poems from sixty-seven professional poets whose work appeared in a collection of Contemporary American Poetry (Poulin and Waters, 2006). These poets produced most of their poems towards the middle and end of the 20th century and are considered some of the best contemporary poets in America. All of the poets we selected are listed in the website of the Academy of American Poets, and many have won prestigious awards (e.g., Louise Gluck, Mary Oliver, Mark Strand) $4^{4}$ We randomly selected one to three poems from each poet, roughly proportional to the number of poems each poet had in the collection. The final selection ranged from 32 to 378 words in length with an average length of 174.15 words (see Appendix for the full list of poets and poems).

\subsection{Results}

We measured the features described in Section 2 for these additional 100 poems written by contemporary professional poets. We began with a simple analysis comparing the feature scores of poems written by 19 th century professional poets and contemporary professional poets. Table 3 shows the average feature scores for these two categories of

\footnotetext{
${ }^{4}$ Since the selection of poems in an anthology is based on the subjective judgments of its editor(s), there are undoubtedly other critically-acclaimed poets whose works were not represented in this particular anthology. However, we hope that we have succeeded in including most of the well-regarded poets in modern times, and invite future work to test our features on poems we may have omitted.
} 


\begin{tabular}{|c|c|c|c|}
\hline Feature & $19 \operatorname{th}(\mathrm{N}=88)$ & Contemporary $(\mathrm{N}=100)$ & Significant? \\
\hline Object & 0.034 & 0.043 & yes \\
\hline Abstract & 0.029 & 0.022 & yes \\
\hline Imageability & 347.399 & 347.803 & no \\
\hline Concreteness & 2.649 & 2.735 & yes \\
\hline Emotion & 0.023 & 0.016 & yes \\
\hline Valence & 5.816 & 5.736 & marginal \\
\hline Arousal & 4.094 & 3.982 & yes \\
\hline IdentityEndRhyme & 0.006 & 0.006 & no \\
\hline PerfectEndRhyme & 0.111 & 0.014 & yes \\
\hline Alliteration & 0.031 & 0.028 & no \\
\hline SlantEndRhyme & 0.080 & 0.097 & marginal \\
\hline Consonance & 0.511 & 0.512 & no \\
\hline Assonance & 0.314 & 0.357 & yes \\
\hline WordLength & 4.104 & 4.158 & no \\
\hline WordFreq & 500.443 & 399.578 & no \\
\hline TypeTokenRatio & 0.665 & 0.669 & no \\
\hline
\end{tabular}

TABLE 3 Average feature scores for poems written by 19th century poets and contemporary professional poets, as well as whether differences between the two groups are statistically significant.

poems, as well as whether the differences are statistically significant.

With respect to the use of concrete imagery, we found that contemporary poems contain significantly more Object words $(t(185.01)=$ $2.87, p<0.005)$ and significantly fewer Abstract words $(t(149.68)=$ $-2.43, p=0.016)$ than 19 th century poems. We also found that contemporary poems score significantly higher on Concreteness $(t(159.58)=$ $3.39, p<0.001)$, although not on Imageability $(t(158.47)=0.14, p=$ 0.89). This suggests that, consistent with the influence of Imagism, modern aesthetic standards are characterized by the presence of concrete imagery to a higher degree than 19th century poems.

In our analysis of emotional language, we found that contemporary poems contain significantly fewer Emotion words than poems by 19 th century poets $(t(162.17)=-2.7, p<0.01)$. Contemporary poems score marginally significantly lower than 19th century poems on Valence $(t(173.3)=-1.95, p=0.053)$. Similarly to Imagist poems, contemporary poems score significantly lower on Arousal $(t(163.38)=$ $-3.71, p<0.0005)$ than 19 th century poems. Together, these results suggest that contemporary poets are less likely to explicitly reference emotions and more likely to use more emotionally subdued and slightly more negative language. While the Emotion and Valence features do not distinguish Imagist poems from 19th century poems, they seem 
to indicate that the contemporary aesthetic involves less emotionally effusive language, perhaps beyond the influence of Imagism.

The sound devices used by 19th century and contemporary poets also differ along several of the features we identified. Contemporary poets used significantly fewer perfect end rhymes $(t(114.08)=$ $-10.76, p<0.00001$ ), which follows naturally from 19th century adherence to stricter poetic forms and rhyme schemes. On the other hand, contemporary poets developed "new rhythms" and new sound patterns by employing more subtle devices such as slant end rhymes $(t(180.6)=1.72, p=0.09)$ and assonance $(t(184.8)=3.97, p<0.0005)$. The two groups of poems did not differ significantly in their use of identity end rhymes $(t(185.66)=-0.17, p=0.86)$, alliteration $(t(158.55)=$ $-1.02, p=0.31)$, or consonance $(t(169.66)=0.06, p=0.95)$.

Finally, our analysis of diction shows that contemporary professional poets did not use significantly shorter $(t(170.86)=1.32, p=0.19)$, more frequent $(t(184.07)=-0.71, p=0.48)$, or more varied words $(t(162.89)=0.28, p=0.78)$ than 19th century poets, suggesting that the literary styles in these two time periods do not differ in terms of the difficulty or diversity of the vocabulary used.

Overall, the comparisons we conducted suggest that contemporary aesthetic standards are more consistent with Imagist sensibilities, particularly in terms of the increase in concreteness, decrease in emotional arousal, and decrease in perfect end rhymes. However, a more detailed analysis of the timing of these changes may help uncover the role of the Imagist movement in establishing these trends. Particularly with regards to concrete imagery, Martindale (1990) proposed that the pressure to be novel naturally requires artists to create work with higher complexity, which can manifest in higher concreteness. If so, this gradual increase in concreteness over time may be responsible for the differences we observe between 19th century and contemporary poems. If time is the best predictor for concreteness, then we would expect the degree of concreteness in a poem to be consistently higher the later it is written, regardless of the Imagism movement. If, on the other hand, Imagism is responsible for promoting concreteness as a critical characteristic of good poetry, then we would expect that poems written prior to the Imagism movement would be uniformly low on concreteness, while poems written after the movement would be uniformly high on concreteness. In other words, we would expect to see a shift in concreteness before and after the Imagism movement, without much systematic variation otherwise.

To test these two hypotheses, we obtained the publication years of 


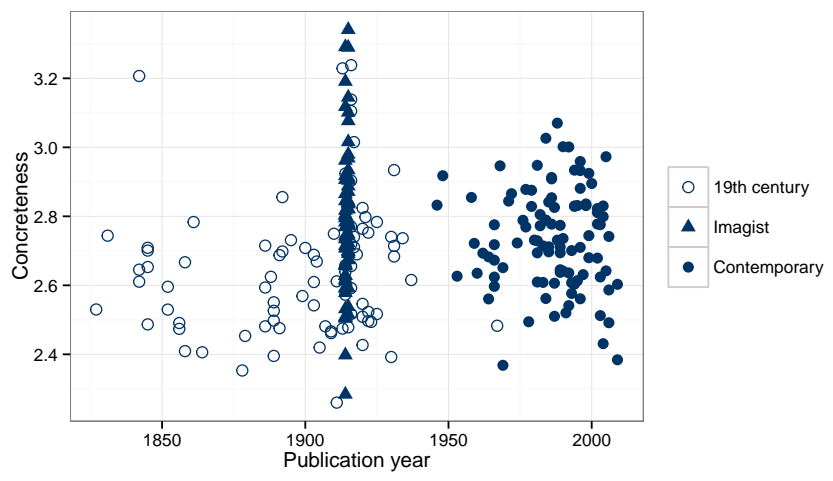

FIGURE 2 Scatter plot of concreteness score vs. publication year for 88 19th century poems, 71 Imagist poems, and 100 contemporary poems. Poems published after the the Imagist movement have significantly higher concreteness scores; however, within each group of poems, there is no positive correlation between publication year and concreteness.

each of the poems $5^{5}$ We first tested whether the concreteness of a poem is correlated with the poem's publication year and found a significant correlation of $r=0.25(p<0.001)$ among the 18819 th century and contemporary poems (not including Imagist poems). This suggests that, overall, poems published later in time contain words with higher concreteness. We then tested whether this correlation is consistent across time, or if there is a significant shift prior to and after the Imagist movement. To do so, we constructed a linear regression model with two predictors: a continuous variable for the publication year, and a binary variable indicating whether the poem was published before the Imagism movement began in 1912. We found that while the binary factor is a significant predictor of concreteness $(t=-3.43, p<0.001)$, publication year does not capture a significant amount of the residual variance $(t=-0.38, p=0.70)$. Among poems published before 1912, there is no significant correlation between concreteness and publication year $(r=-0.22, p=0.15)$; among poems published after 1912, there is also no significant correlation between concreteness and publication year $(r=0.016, p=0.85)$. Figure 2 shows the relationship between the poem's publication year and its concreteness. Our analysis suggests that, contrary to Martindale (1990)'s hypothesis that poetry naturally trends towards higher concreteness over time, a more likely explanation

\footnotetext{
${ }^{5}$ For some of these poems, it was difficult to obtain reliable publication years. In
} those cases, we estimated the publication year by choosing the poet's midlife point. 


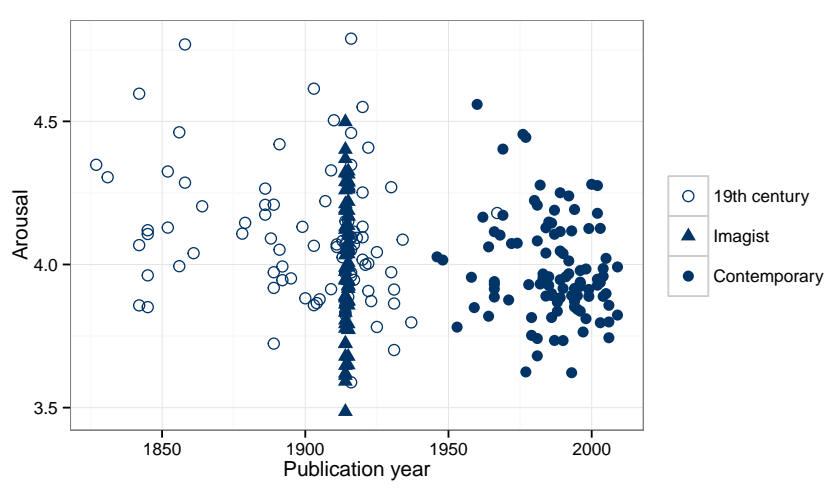

FIGURE 3 Scatter plot of arousal score vs. publication year for 88 19th century poems, 71 Imagist poems, and 100 contemporary poems. Following

the Imagist movement, poems scored increasingly lower on emotional arousal.

for this set of data is that a shift towards concreteness occurred after the Imagism movement.

We conducted a similar time series analysis for emotional arousal. We found a strong negative correlation between publication year and arousal across 19th century and contemporary poems $(r=-0.33, p<$ $0.00001)$, suggesting that poems published later in time tend to express lower emotional arousal. While there is no significant correlation between publication year and arousal among poems published before $1912(r=-0.19, p=0.20)$, the arousal scores of poems published after 1912 continued to decline $(r=-0.21, p=0.01)$ (Figure 3). Whether this trend will continue into the 21 st century is an interesting area for future research.

\section{Study 3: Contemporary professional vs. amateur poets}

Our results from Study 2 suggest that the Imagism movement had a marked influence on the styles of contemporary professional poets. However, to examine the effect of Imagism on the modern aesthetic in a more holistic manner, it is important to consider whether amateur poets writing in modern times were similarly affected by Imagist ideals. Furthermore, by comparing poems written by professional versus amateur poets, we can shed light on whether the same features that distinguish contemporary professional poems from older poems also distinguish professional poems from amateur poems, a pattern that may 
have implications on the nature and direction of artistic change.

Many literary movements in the late 19th century were intentionally targeted at professional writers to create an atmosphere of exclusivity (Thacker, 2011). While amateur poets may seek to emulate elite poetry, it is more difficult for them to access the latest styles; as a result, their impression of good poetry is more likely to be shaped by the styles of the previous era. When amateur poets later produce poetry of their own, they may tend to emulate these more "outdated" styles. Following this reasoning, we predicted that poems written by contemporary amateur poets would more closely resemble poems written by 19 th century poets, and thus lack characteristics of the Imagist aesthetic. In this section, we explore the dynamics between professional and amateur poetry by examining the presence of Imagist ideals in poems written by contemporary amateur poets.

\subsection{Materials and methods}

We randomly selected 100 poems written by amateur poets who submitted their work anonymously to a free and uncurated website, aptly called "Amateur Writing" (http://www.amateur-writing.com) ${ }^{6}$ The website contains a diverse set of poems submitted by amateur writers with a wide range of experience and skill levels 7 At the time of selection, the website had over 2500 amateur poem submissions by registered users. The final selection of 100 amateur poems ranged from 21 to 353 words in length with an average length of 137.52 words (see Appendix for the full list of poem titles).

\subsection{Results}

For each of the 100 amateur poems, we computed the 16 feature scores described in Section 2. Figure 1 shows the mean scores for each of the 16 features, while Table 4 indicates whether the scores significantly differ from those of 19 th century poems.

In our analyses, we found that amateur poems do not differ significantly from 19th century poems in terms of Object words $(t(183.63)=$ $-1.26, p=0.21)$ or Abstract words $(t(183.59)=1.47, p=0.142)$.

\footnotetext{
${ }^{6}$ While it is possible that professional poets may also submit their poems to this website, it is reasonable to assume that most poets who submit to this website are not professionally trained, or at least are not held to the same standards as poets whose works are anthologized.

${ }^{7}$ Poems submitted to this website do not undergo a reviewing or editing process; as a result, it is natural for these poems to contain more errors. Since mispellings result in more out-of-vocabulary words, which affect our analyses, we manually corrected these errors in order to reduce the difference in basic language correctness between professional and amateur poems.
} 


\begin{tabular}{lrrr}
\hline Feature & 19th $(\mathrm{N}=88)$ & Amateur $(\mathrm{N}=100)$ & Significant? \\
\hline Object & 0.034 & 0.030 & no \\
Abstract & 0.029 & 0.034 & no \\
Imageability & 347.399 & 341.412 & yes \\
Concreteness & 2.649 & 2.572 & yes \\
\hline Emotion & 0.023 & 0.031 & yes \\
Valence & 5.816 & 5.981 & yes \\
Arousal & 4.094 & 4.130 & no \\
\hline IdentityEndRhyme & 0.006 & 0.029 & yes \\
PerfectEndRhyme & 0.111 & 0.080 & yes \\
Alliteration & 0.031 & 0.031 & no \\
SlantEndRhyme & 0.080 & 0.087 & no \\
Consonance & 0.511 & 0.458 & yes \\
Assonance & 0.314 & 0.323 & no \\
\hline WordLength & 4.104 & 3.921 & yes \\
WordFreq & 500.443 & 708.123 & no \\
TypeTokenRatio & 0.665 & 0.610 & yes \\
\hline
\end{tabular}

TABLE 4 Average feature scores for poems written by 19th century poets and contemporary amateur poets, as well as whether differences between the two groups are statistically significant.

However, amateur poems contain words with significantly lower Imageability $(t(146.48)=-2.15, p=0.03)$ and Concreteness $(t(165.43)=$ $-3.01, p=0.003)$ than 19 th century poems. Amateur poems also tend to contain significantly more Emotion words $(t(185.44)=2.91, p=$ $0.004)$ and words with more positive Valence $(t(176)=3.08, p=0.002)$ than 19th century poems. On the other hand, amateur poems and 19th century poems do not differ significantly in terms of emotional Arousal $(t(181.42)=1.10, p=0.27)$. Amateur poets tend to use fewer PerfectEndRhymes than 19th century professional poets $(t(173)=$ $-2.89, p=0.004)$, but still significantly more than contemporary professional poets $(t(144.06)=8.73, p<0.00001)$. Finally, amateur poems contain significantly shorter words $(t(185.98)=-3.83, p=0.0002)$ as well as a less diverse vocabulary $(t(180.13)=-3.33, p=0.001)$ than poems written by 19th century professional poets. Across these features, it appears that poems written by contemporary amateur poets exhibit fewer instances of Imagist ideals than poems written by either group of professional poets.

To visualize the differences between 19th century poems, Imagist poems, contemporary professional poems, and contemporary amateur poems, we used Principal Component Analysis to project each poem 
onto a two-dimensional space based on their 16 features scores. While the first two principal components only capture $16.5 \%$ and $11 \%$ of the total variance, respectively, we can still observe some interesting differences between the four groups of poems along these two principal dimensions. Consistent with our predictions and earlier analyses, Imagist poems tend to cluster along the direction of higher Imageability, Concreteness, and Object scores, while contemporary amateur poems tend to cluster along the direction of higher IdentityEndRhyme, Valence, Emotion, and PerfectEndRhyme. Moreover, while the standard error ellipse for contemporary professional poems lies within the ellipse for Imagist poems, indicating high similarity in this projected space, the ellipses for 19th century and contemporary amateur poems lie farther away. This analysis gives us further insight into the relative similarities among poems written by these four groups of poets, as well as the features that characterize them. Overall, our data suggests that contemporary professional poems adhere more to the Imagist aesthetic, while contemporary amateur poems are more similar to 19th century poems and stray even further from Imagist ideals.

\section{Discussion}

In this paper, we quantified the aesthetic ideals of Imagism using computational linguistics techniques and evaluated the degree of conformity to these ideals in four sets of English poems: poems written by 19th century professional poets, Imagist poets, contemporary professional poets, and contemporary amateur poets. Our analyses reveal several interesting insights on Imagism and its effect on the modern literary aesthetic. First, poems written by contemporary professional poets exhibit significantly more features of Imagism than poems written by 19 th century professional poets. This suggests that even though the Imagist movement itself was short-lived, the modern literary aesthetic has adopted Imagist ideals and moved away from the more abstract, emotional, and rhyme-schemed style of the 19th century. Second, while some theories of artistic change claim that the use of concrete imagery may be a natural consequence of the pressure to be novel (Martindale, 1990), a more detailed analysis of concreteness suggests that the Imagist movement may have been responsible for promoting the use of concrete imagery, above and beyond a uniform pressure of time.

Although contemporary professional poets have adopted Imagist ideals, we found that contemporary amateur poems reflect the Imagist ideal to an even lesser degree than 19th century poems. This finding brings up an interesting and rather controversial point about the na- 
A Computational Analysis of Poetic Style / 21

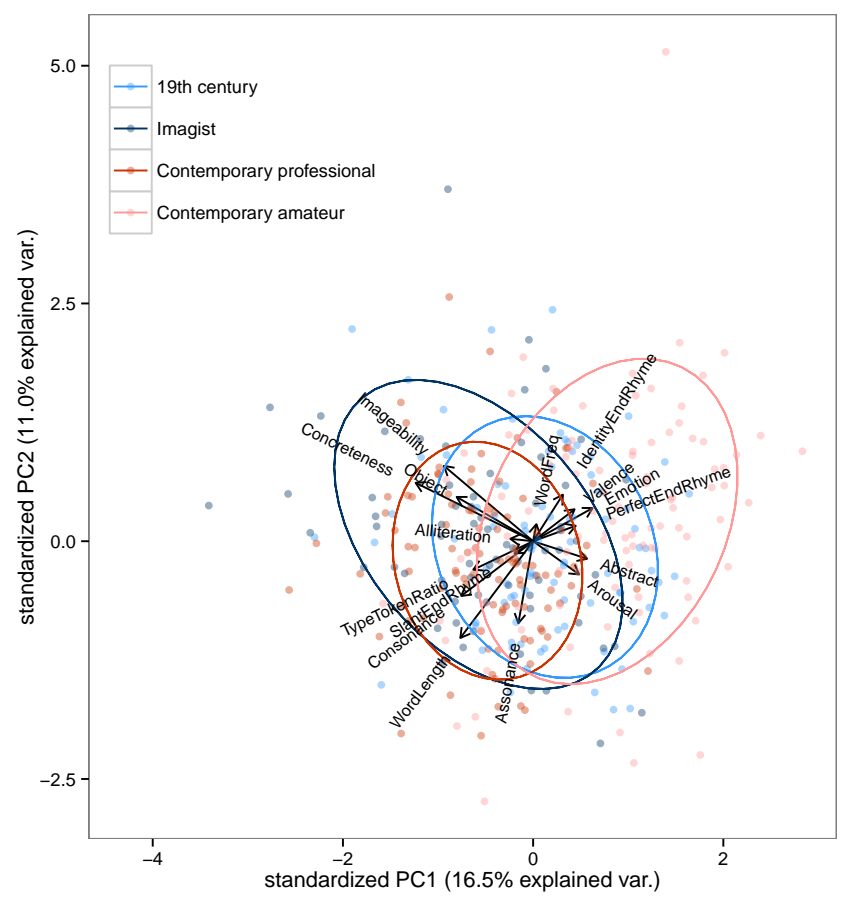

FIGURE 4 Biplot and standard error ellipses of the 359 19th century poems, Imagist poems, contemporary professional poems, and contemporary amateur poems along the first two principal components. 
ture of art and artistic change. "Great poetry," the poet T.E. Hulme argued, "always endeavors to arrest you, and to make you continuously see a physical thing, to prevent you from gliding through an abstract process." Perhaps the reason why amateur poets exhibit fewer features of Imagism than 19th century professional poets is because the Imagist aesthetic correlates with higher sophistication, and is thus less likely to be mastered by amateur poets who lack the proper skill and training. It is possible that the style of contemporary professional poets is in a sense more "advanced" than the style of 19th century professional poets, which in turn is more advanced than amateur poets. This explanation suggests that the Imagist aesthetic not only happens to be the prominent aesthetic in modern times, but is a better and more desirable aesthetic than the ones in the past. Indeed, the appeal of concrete imagery may have roots in processes that facilitate learning and memory. Research in psychology has shown that concrete noun pairs are easier to memorize than abstract noun pairs, and that mental imagery facilitates stronger association between concepts (Paivio et al., 1966, Bower, 1970). One of the reasons why we find poetic imagery striking may be its ability to evoke rich associations formed by culture and personal experience. The mark of a skilled poet may then be his or her ability to pick out specific sensory details that allow readers to access these experiences and form their own personalized interpretations.

On the other hand, some views on artistic change would disagree with the claim that the contemporary imagery-centric aesthetic is superior to poetic styles of the past. According to Lowell (1920), "Fundamental beliefs change art, but do not, necessarily, either improve or injure it. Great poetry has been written at every stage of the world's history, but Homer did not write like Dante, nor Dante like Shakespeare, nor Shakespeare like Edgar Allan Poe." While our data is unable to conclusively validate the inherent value of Imagist ideals, it supports the idea that Imagism has strongly influenced the ways in which modern professional poets conceptualize poetic language and may have helped establish the modern preference for concreteness.

Our analysis of sound devices also provides interesting insight into the current stylistic trends of contemporary professional poetry. Sound devices have a long history in poetry and are traditionally considered an important aspect of poetic craft. However, contemporary professional poets now use these devices much less frequently than either 19th century poets or contemporary amateur poets. Sound devices that were traditionally important for mnemonic purposes are now more characteristic of amateur poetry. These results suggest that repetition of sound is becoming a less aesthetically significant poetic device among con- 
temporary masters of poetry. Instead, imagistic patterns have largely displaced sound patterns and risen to power as the primary indicator of poetic language.

The tools and methodology in this work enabled us to operationalize the Imagist aesthetic and test its influence on a large number of poems. By examining the claim that Imagism gave rise to the modern aesthetic (Pratt, 1992), our work highlights the benefits of applying computational approaches to questions in the humanities. Without the fine-grained measurements that these tools provide, it would be difficult to tease apart two competing hypotheses regarding the increasing levels of concreteness in poetry: whether it is a natural consequence of artistic evolution, or whether the Imagism movement was responsible for initiating and sustaining this change. Furthermore, we showed that the lexicons used in psycholinguistics and natural language processing capture textual qualities that are important in literary analysis, such as imagery and sentiment, and that these measures can identify important trends in literary style. Finally, the computational nature of our analyses means that we can apply the same features and measurements to different set of poems and replicate or extend our findings.

Computational techniques have been applied to analyze literary style in many ways. Holmes (1985) discussed the benefits of quantitative measures of style, and Stamatatos et al. (2000) used stylistic measures to automatically classify texts into different genres and authors. More recently, Kaplan and Blei (2007) developed a computer program to visualize and compare the styles of different American poets, some of the features of which we incorporated in this work. Although we drew upon the insights of these previous studies, our approach was somewhat more theory-driven. We selected measures directly based on the tenets of a specific literary style and investigated the impact that this style had on later work. Given this top-down approach, we hope that our findings are interpretable and useful to scholars in the humanities, since the relationship between a tenet - "to present an image" - and its operationalization-word-level concreteness ratings-was designed to be sufficiently clear.

While we focused on poetic style in this paper, the results of our work regarding the differences between professional and amateur poetry are consistent with recent computational studies of literary style in prose. Ashok et al. (2013), for example, found lexical and syntactic features that correlate with literary success in novels: more successful novels used more verbs and discourse connectives, while less successful ones used more sentiment-laden words like "love". On the other hand, we have not examined whether the differences we found between 19th century 
and contemporary poems exist in other genres written in those times; as a result, our data does not allow us to conclude that these changes are specific to poetic language. It would be interesting for future work to compare historical trends in other genres as well.

While our analyses shed light on the contemporary literary aesthetic and its relationship to the Imagist movement, it leaves open many questions to investigate in future research. For example, of the many literary movements of the late 19th century, why did Imagism leave such a distinct mark on modern poetic styles? What other factors, such as the pressure to publish or the historical context of these movements, do we need to consider in order to situate isolated stylistic features in a broader context? Are contemporary amateur poets also beginning to adopt Imagist ideals, such that amateur poetry written more recently exhibit more concrete imagery and fewer sound devices than amateur poetry written in the last decade? Would modifying a professional poem to include fewer concrete words make modern readers perceive it to be less beautiful? Is it easier for people to memorize poems that contain more concrete words, in much the same way that it is easier to memorize poems with stricter rhyme schemes? These questions have important implications on theories of artistic change, the relationship between elite and mainstream literature, and the historical and psychological bases of aesthetic appreciation. Our work provides a novel way of using computational methods to begin answering these questions in an empirical and data-driven manner. By conducting a quantitative comparison of poetic style across time and expertise, we hope to contribute to a deeper understanding of the forces that shape great poetry throughout the ages.

\section{Acknowledgments}

This work was supported by an NSF Graduate Research Fellowship to Justine Kao and NSF grant IIS-1159679 to Dan Jurafsky. We are deeply grateful for David Kaplan's generosity in sharing the code for the PoetryAnalyzer program, on which a substantial part of our analysis is based. We thank the reviewers of this paper for their extremely helpful feedback, as well as comments from Lera Boroditsky, Chris Potts, Todd Davies, and Noah Goodman during earlier stages of this work. 


\section{References}

Addonizio, K. and D. Laux. 1997. The Poet's Companion: A guide to the pleasures of writing poetry. W. W. Norton and Company.

Aldington, Richard, Hilda Doolittle, John Gould Fletcher, Frank Stewart Flint, David Herbert Lawrence, and Amy Lowell. 1916. Some Imagist Poets: An Anthology, vol. 2. Houghton Mifflin Company.

Ashok, Vikas G., Song Feng, and Yejin Choi. 2013. Success with Style: Using Writing Style to Predict the Success of Novels. In EMNLP 2013, pages 1753-1764.

Baumann, Shyon. 2007. A general theory of artistic legitimation: How art worlds are like social movements. Poetics 35(1):47-65.

Ben-Simon, A. and R. E. Bennett. 2007. Toward More Substantively Meaningful Automated Essay Scoring. The journal of Technology, Learning, and Assessment .

Bower, G.H. 1970. Imagery as a relational organizer in associative learning. Journal of Verbal Learning and Verbal Behavior 9(5):529-533.

Breland, Hunter M. 1996. Word Frequency and Word Difficulty: A Comparison of Counts in Four Corpora. Psychological Science 7(2):pp. 96-99.

Brysbaert, Marc, Amy Beth Warriner, and Victor Kuperman. 2013. Concreteness ratings for 40 thousand generally known English word lemmas. Behavior research methods pages 1-8.

Burroway, J. 2007. Imaginative Writing: The Elements of Craft. Pearson, 2nd edn.

Clayton, Jay and Eric Rothstein. 1991. Influence and intertextuality in literary history. Univ of Wisconsin Press.

Coltheart, M. 1981. The MRC psycholinguistic database. The Quarterly Journal of Experimental Psychology 33(4):497-505.

Davies, M. 2011. Word frequency data from the Corpus of Contemporary American English (COCA). Downloaded from http://www.wordfrequency.info on May 10, 2011.

Frank, Joseph. 1991. The idea of spatial form. Rutgers University Press.

Hamilton, Craig A. 2004. Toward a Cognitive Rhetoric of Imagism. Style 38(4):468.

Holmes, David I. 1985. The analysis of literary style-a review. Journal of the Royal Statistical Society. Series A (General) pages 328-341.

Isaac, Larry. 2009. Movements, aesthetics, and markets in literary change: Making the American labor problem novel. American Sociological Review 74(6):938-965.

Kaplan, D. 2006. Computational Analysis and Visualized Comparison of Style in American Poetry. Unpublished undergraduate thesis.

Kaplan, D. and D. Blei. 2007. A computational approach to style in American poetry. In IEEE Conference on Data Mining. 
Levenson, Michael. 1986. A Genealogy of Modernism: A study of English literary doctrine 1908-1922. Cambridge University Press.

Lowell, Amy. 1915. Some Imagist Poets. London. Constable .

Lowell, Amy. 1920. Tendencies in modern American poetry. Macmillan.

Martindale, Colin. 1990. The clockwork muse: The predictability of artistic change.. Basic Books.

Paivio, A., J.C. Yuille, and P.C. Smythe. 1966. Stimulus and response abstractness, imagery, and meaningfulness, and reported mediators in pairedasscoiate learning. Canadian Journal of Psychology 20(4).

Pitler, E. and Nenkova, Ani. 2008. Revisiting readability: A unified framework for predicting text quality. In Empirical Methods in Natural Language Processing, pages 186-195.

Poulin, A. and M. Waters. 2006. Contemporary American Poetry. Houghton Mifflin Company, eighth edn.

Pound, Ezra. 1914. Des Imagistes. London, Charles and Albert Boni .

Pratt, William. 1992. Imagism and the Shape of English Poetry. Pratt, $W$. and Richardson, R. eds pages 75-96.

Simmel, Georg. 1957. Fashion. American journal of sociology pages 541-558.

Stamatatos, Efstathios, Nikos Fakotakis, and George Kokkinakis. 2000. Automatic text categorization in terms of genre and author. Computational linguistics 26(4):471-495.

Stone, P.J., D.C. Dunphry, M.S. Smith, and D.M. Ogilvie. 1966. The General Inquirer: A Computer Approach to Content Analysis. Cambridge, MA: MIT Press.

Thacker, AJ. 2011. The imagist poets. Northcote House.

Warriner, Amy Beth, Victor Kuperman, and Marc Brysbaert. 2013. Norms of valence, arousal, and dominance for 13,915 English lemmas. Behavior research methods 45(4):1191-1207.

Wilson, Michael. 1988. MRC Psycholinguistic Database: Machine-usable dictionary, version 2.00. Behavior Research Methods, Instruments, ES Computers 20(1):6-10. 


\section{Appendix: List of poems}

\section{9th century professional}

88 poems written by poets born between 1801 and 1900. Taken from "Famous Poets and Poems" (http://famouspoetsandpoems.com).

\begin{tabular}{|c|c|c|c|}
\hline No. & Poem title & Poet & $\begin{array}{l}\text { Publication } \\
\text { year }\end{array}$ \\
\hline 1 & $\begin{array}{l}\text { From The Short Story What The } \\
\text { Swallows Did }\end{array}$ & Louisa May Alcott & 1864 \\
\hline 2 & Turns And Movies: Zudora & Conrad Aiken & 1916 \\
\hline 3 & The Window & Conrad Aiken & 1916 \\
\hline 4 & Before an Examination & Stephen Vincent Benet & 1920 \\
\hline 5 & Lonely Burial & Stephen Vincent Benet & 1920 \\
\hline 6 & Knowledge & Louise Bogan & 1922 \\
\hline 7 & Weather & Ambrose Bierce & 1878 \\
\hline 8 & A Woman's Reason & Gelett Burgess & 1903 \\
\hline 9 & The Goops & Gelett Burgess & 1900 \\
\hline 10 & The Sheep & Ellis Parker Butler & 1903 \\
\hline 11 & Cupid Caught Napping & Ellis Parker Butler & 1899 \\
\hline 12 & In the desert & Stephen Crane & 1895 \\
\hline 13 & A god in wrath & Stephen Crane & 1886 \\
\hline 14 & Upon the road of my life & Stephen Crane & 1886 \\
\hline 15 & Once I knew a fine song & Stephen Crane & 1886 \\
\hline 16 & To Emily Dickinson & Hart Crane & 1916 \\
\hline 17 & Interior & Hart Crane & 1916 \\
\hline 18 & If I can stop one Heart from breaking & Emily Dickinson & 1914 \\
\hline 19 & I felt a Funeral in my Brain & Emily Dickinson & 1914 \\
\hline 20 & We lose - because we win & Emily Dickinson & 1914 \\
\hline 21 & Going to Heaven! & Emily Dickinson & 1914 \\
\hline 22 & There is no Frigate like a Book & Emily Dickinson & 1914 \\
\hline 23 & Life's Tragedy & Paul Laurence Dunbar & 1889 \\
\hline 24 & Encouraged & Paul Laurence Dunbar & 1889 \\
\hline 25 & The Unlucky Apple & Paul Laurence Dunbar & 1889 \\
\hline 26 & A Noon Song & Henry Van Dyke & 1911 \\
\hline 27 & God of the Open Air & Henry Van Dyke & 1920 \\
\hline 28 & Indian Summer & Henry Van Dyke & 1911 \\
\hline 29 & Farewell and Thanksgiving & Mark van Doren & 1967 \\
\hline 30 & Give All To Love & Ralph Waldo Emerson & 1842 \\
\hline 31 & The Park & Ralph Waldo Emerson & 1842 \\
\hline 32 & Threnody & Ralph Waldo Emerson & 1842 \\
\hline 33 & The Road Not Taken & Robert Frost & 1918 \\
\hline 34 & Mending Wall & Robert Frost & 1916 \\
\hline 35 & My November Guest & Robert Frost & 1915 \\
\hline 36 & A Valentine & Eugene Field & 1914 \\
\hline 37 & Horace to phyllis & Eugene Field & 1889 \\
\hline 38 & The Boys & Oliver Wendell Holmes & 1852 \\
\hline 39 & The Organ-Blower & Oliver Wendell Holmes & 1852 \\
\hline 40 & End of The World & Robinson Jeffers & 1925 \\
\hline 41 & Promise Of Peace & Robinson Jeffers & 1925 \\
\hline 42 & A Dream & Helen Hunt Jackson & 1858 \\
\hline 43 & My Tenants & Helen Hunt Jackson & 1858 \\
\hline 44 & Poets & Joyce Kilmer & 1913 \\
\hline 45 & The Rainy Day & Henry Wadsworth Longfellow & 1845 \\
\hline 46 & Woods in Winter & Henry Wadsworth Longfellow & 1845 \\
\hline 47 & The Three Kings & Henry Wadsworth Longfellow & 1845 \\
\hline 48 & Wapentake & Henry Wadsworth Longfellow & 1845 \\
\hline 49 & Drying Their Wings & Vachel Lindsay & 1913 \\
\hline 50 & To Lady Jane & Vachel Lindsay & 1920 \\
\hline 51 & A Curse for Kings & Vachel Lindsay & 1915 \\
\hline 52 & City Visions & Emma Lazarus & 1888 \\
\hline 53 & The Taming of the Falcon & Emma Lazarus & 1879 \\
\hline 54 & A Dedication. To Charlotte Cushman & Sidney Lanier & 1892 \\
\hline 55 & To Beethoven & Sidney Lanier & 1892 \\
\hline 56 & A Red Flower & Claude McKay & 1922 \\
\hline 57 & On the Road & Claude McKay & 1922 \\
\hline 58 & Love Is Not All & Edna St. Vincent Millay & 1931 \\
\hline 59 & The Suicide & Edna St. Vincent Millay & 1917 \\
\hline 60 & Griffy the Cooper & Edgar Lee Masters & 1916 \\
\hline 61 & Emily Sparks & Edgar Lee Masters & 1916 \\
\hline 62 & Poem in Prose & Archibald MacLeish & 1937 \\
\hline 63 & The Enthusiast & Herman Melville & 1891 \\
\hline 64 & Song & Edgar Allan Poe & 1827 \\
\hline 65 & The Valley Of Unrest & Edgar Allan Poe & 1831 \\
\hline
\end{tabular}




\begin{tabular}{llll}
\hline 66 & A Fairly Sad Tale & Dorothy Parker & 1930 \\
67 & Dilemma & Dorothy Parker & 1930 \\
68 & Miniver Cheevy & Edwin Arlington Robinson & 1910 \\
69 & Lancelot & Edwin Arlington Robinson & 1921 \\
70 & Painted Head & John Crowe Ransom & 1931 \\
71 & Happiness & Carl Sandburg & 1916 \\
72 & Horse Fiddle & Carl Sandburg & 1920 \\
73 & The Idea Of Order At Key West & Wallace Stevens & 1934 \\
74 & Nomad Exquisite & Wallace Stevens & 1923 \\
75 & Do You Remember Once & Alan Seeger & 1917 \\
76 & To England at the Outbreak of the Balkan War & 1917 \\
77 & After Love & Alan Seeger & 1909 \\
78 & The Years & Sara Teasdale & 1909 \\
79 & Prayer & Sara Teasdale & 1903 \\
80 & Tell Me & Henry David Thoreau \\
81 & O Captain! My Captain! & Jean Toomer & 1931 \\
82 & Beginners & Walt Whitman & 1891 \\
83 & Inscription & Walt Whitman & 1856 \\
84 & A Golden Day & Walt Whitman & 1856 \\
85 & Our Blessings & Ella Wheeler Wilcox \\
86 & A Word for the Hour & Ella Wheeler Wilcox & 1905 \\
87 & The Old Guitar & John Greenleaf Whittier & 1904 \\
88 & Silver Filigree & James Whitcomb Riley & 1861 \\
\hline
\end{tabular}

\section{Imagist}

71 Imagist poems published in Des Imagistes (1914) and Some Imagist Poets (1915).

\begin{tabular}{|c|c|c|c|}
\hline No. & Poem title & Poet & Publication year \\
\hline 1 & Choricos & Richard Aldington & 1914 \\
\hline 2 & To a Greek Marble & Richard Aldington & 1914 \\
\hline 3 & Au Vieux Jardin & Richard Aldington & 1914 \\
\hline 4 & Lesbia & Richard Aldington & 1914 \\
\hline 5 & Beauty Thou Aast Hurt Me Overmuch & Richard Aldington & 1914 \\
\hline 6 & Argyria & Richard Aldington & 1914 \\
\hline 7 & In the Via Sestina & Richard Aldington & 1914 \\
\hline 8 & The River & Richard Aldington & 1914 \\
\hline 9 & Bromios & Richard Aldington & 1914 \\
\hline 10 & To Atthis & Richard Aldington & 1914 \\
\hline 11 & Sitalkas & H.D. & 1914 \\
\hline 12 & Hermes of the Ways & H.D. & 1914 \\
\hline 13 & Priapus & H.D. & 1914 \\
\hline 14 & Acon & H.D. & 1914 \\
\hline 15 & Hermonax & H.D. & 1914 \\
\hline 16 & Epigram & H.D. & 1914 \\
\hline 17 & I & S.F. Flint & 1914 \\
\hline 18 & Hallucination & S.F. Flint & 1914 \\
\hline 19 & III & S.F. Flint & 1914 \\
\hline 20 & IV & S.F. Flint & 1914 \\
\hline 21 & The Swan & S.F. Flint & 1914 \\
\hline 22 & Nocturnes & Skipwith Cannell & 1914 \\
\hline 23 & In a Garden & Amy Lowell & 1914 \\
\hline 24 & Postlude & William Carlos Williams & 1914 \\
\hline 25 & I Hear an Army & James Joyce & 1914 \\
\hline 26 & A'Opia & Ezra Pound & 1914 \\
\hline 27 & thereturn & Ezra Pound & 1914 \\
\hline 28 & After Cwu Yuan & Ezra Pound & 1914 \\
\hline 29 & Liu Ch'E & Ezra Pound & 1914 \\
\hline 30 & Fan-piece for her Imperal Lord & Ezra Pound & 1914 \\
\hline 31 & Ts'ai Chfh & Ezra Pound & 1914 \\
\hline 32 & In the Little Old Marketplace & Ford Madox Hueffer & 1914 \\
\hline 33 & Scented Leaves from Chinese Jar & Allen Upward & 1914 \\
\hline 34 & The Rose & John Cournos & 1914 \\
\hline 35 & Childhood & Richard Aldington & 1915 \\
\hline 36 & The Poplar & Richard Aldington & 1915 \\
\hline 37 & Round-pond & Richard Aldington & 1915 \\
\hline 38 & Daisy & Richard Aldington & 1915 \\
\hline 39 & Epigrams & Richard Aldington & 1915 \\
\hline 40 & The Faun Sees Snow for the First Time & Richard Aldington & 1915 \\
\hline 41 & Lemures & Richard Aldington & 1915 \\
\hline
\end{tabular}




\begin{tabular}{llll}
\hline 42 & The Pool & H.D. & 1915 \\
43 & The Garden & H.D. & 1915 \\
44 & Sea Lily & H.D. & 1915 \\
45 & Sea Iris & H.D. & 1915 \\
46 & Sea Rose & H.D. & 1915 \\
47 & Oread & H.D. & 1915 \\
48 & Orion Dead & H.D. & 1915 \\
49 & The Blue Symphony & John Gould Fletcher & 1915 \\
50 & London Excursion & John Gould Fletcher & 1915 \\
51 & Trees & F. S. Flint & 1915 \\
52 & Lunch & F. S. Flint & 1915 \\
53 & Malady & F. S. Flint & 1915 \\
54 & Accident & F. S. Flint & 1915 \\
55 & Fragmat & F. S. Flint & 1915 \\
56 & Houses & F. S. Flint & 1915 \\
57 & Eau-Forte & F. S. Flint & 1915 \\
58 & Ballad of Another Ophelia & D.H. Lawrence & 1915 \\
59 & Illicit & D.H. Lawrence & 1915 \\
60 & Fireflies in the Corn & D.H. Lawrence & 1915 \\
61 & A Woman and her Dead Husband & D.H. Lawrence & 1915 \\
62 & The Mowers & D.H. Lawrence & 1915 \\
63 & Scent of Irises & D.H. Lawrence & 1915 \\
64 & Green & D.H. Lawrence & 1915 \\
65 & Venus Transiens & Amy Lowell & 1915 \\
66 & The Travelling Bear & Amy Lowell & 1915 \\
67 & The Letter & Amy Lowell & 1915 \\
68 & Grotesque & Amy Lowell & 1915 \\
69 & Bullion & Amy Lowell & 1915 \\
70 & Solitaire & Amy Lowell & 1915 \\
71 & The Bombardment & Amy Lowell & 1915 \\
\hline
\end{tabular}

\section{Contemporary professional}

100 poems taken from Contemporary American Poetry (Poulin and Waters, 2006).

\begin{tabular}{|c|c|c|c|}
\hline No. & Poem title & Poet & $\begin{array}{l}\text { Publication } \\
\text { year }\end{array}$ \\
\hline 1 & Riot Act April 291992 & $\mathrm{Ai}$ & 1993 \\
\hline 2 & Twenty-year Marriage & $\mathrm{Ai}$ & 1999 \\
\hline 3 & To Dorothy & Marvin Bell & 1981 \\
\hline 4 & To an Adolescent Weeping Willow & Marvin Bell & 1981 \\
\hline 5 & Dream Song 26: The glories of the world struck me & John Berryman & 1969 \\
\hline 6 & Dream Song 172: Your face broods & John Berryman & 1969 \\
\hline 7 & The Fish & Elizabeth Bishop & 1946 \\
\hline 8 & Warning to the Reader & Robert Bly & 1992 \\
\hline 9 & The Russian & Robert Bly & 1966 \\
\hline 10 & A Lovely Love & Gwendolyn Brooks & 1959 \\
\hline 11 & The Choir & Olga Broumas & 1987 \\
\hline 12 & $\begin{array}{l}\text { at the cemetery walnut grove plantation } \\
\text { south carolina } 1989\end{array}$ & Lucille Clifton & 1989 \\
\hline 13 & scar & Lucille Clifton & 1996 \\
\hline 14 & Japan & Billy Collins & 2006 \\
\hline 15 & Writing in the Afterlife & Billy Collins & 1991 \\
\hline 16 & The Language & Robert Creeley & 1987 \\
\hline 17 & The Warning & Robert Creeley & 1960 \\
\hline 18 & Adultery & James Dickey & 1962 \\
\hline 19 & Tomatoes & Stephen Dobyns & 1987 \\
\hline 20 & Fragments & Stephen Dobyns & 1979 \\
\hline 21 & Wingfoot Lake & Rita Dove & 1964 \\
\hline 22 & The Stairway & Stephen Dunn & 2006 \\
\hline 23 & The Strange People & Louise Erdrich & 2003 \\
\hline 24 & New Vows & Louise Erdrich & 1984 \\
\hline 25 & Sexual Jealousy & Carol Frost & 1994 \\
\hline 26 & The Undressing & Carol Frost & 1994 \\
\hline 27 & To Kill a Deer & Carol Frost & 2000 \\
\hline 28 & Nostos & Louise Gluck & 1997 \\
\hline 29 & Celestial Music & Louise Gluck & 1990 \\
\hline 30 & How Simile Works & Albert Goldbarth & 2009 \\
\hline 31 & The Older Child & Kimiko Hahn & 1992 \\
\hline 32 & The Porcelain Couple & Donald Hall & 1996 \\
\hline 33 & Reuben Reuben & Michael S. Harper & 1977 \\
\hline
\end{tabular}




\begin{tabular}{|c|c|c|c|}
\hline 34 & Our Lady of the Snows & Robert Hass & 1996 \\
\hline 35 & The Image & Robert Hass & 1999 \\
\hline 36 & Those Winter Sundays & Robert Hayden & 1966 \\
\hline 37 & This Night & William Heyen & 1977 \\
\hline 38 & Playing Dead & Andrew Hudgins & 2005 \\
\hline 39 & Degrees Of Gray In Philipsburg & Richard Hugo & 1984 \\
\hline 40 & Absences & Donald Justice & 2006 \\
\hline 41 & Variations On A Text By Vallejo & Donald Justice & 1995 \\
\hline 42 & After Making Love we Hear Footsteps & Galway Kinnell & 2002 \\
\hline 43 & Blackberry Eating & Galway Kinnell & 1980 \\
\hline 44 & Thrall & Carolyn Kizer & 1986 \\
\hline 45 & The Intruder & Carolyn Kizer & 1986 \\
\hline 46 & Facing It & Yusef Komunyakaa & 1988 \\
\hline 47 & Audacity of the Lower Gods & Yusef Komunyakaa & 2004 \\
\hline 48 & Heaven as Anus & Maxine Kumin & 1989 \\
\hline 49 & Nurture & Maxine Kumin & 1989 \\
\hline 50 & The Abduction & Stanley Kunitz & 1985 \\
\hline 51 & My Indigo & Li-Young Lee & 1986 \\
\hline 52 & Eating Alone & Li-Young Lee & 1986 \\
\hline 53 & The Mutes & Denise Levertov & 1966 \\
\hline 54 & Wedding-Ring & Denise Levertov & 1978 \\
\hline 55 & They Feed They Lion & Philip Levine & 1972 \\
\hline 56 & Animals Are Passing From Our Lives & Philip Levine & 1968 \\
\hline 57 & To Speak of Woe That Is in Marriage & Robert Lowell & 1976 \\
\hline 58 & Onions & William Matthews & 1989 \\
\hline 59 & Charles on Fire & James Merrill & 1966 \\
\hline 60 & $\mathrm{~b} \circ \mathrm{d} \mathrm{y}$ & James Merrill & 1996 \\
\hline 61 & For the Anniversary of My Death & W.S. Merwin & 1993 \\
\hline 62 & When You Go Away & W.S. Merwin & 1993 \\
\hline 63 & Minor Miracle & Marilyn Nelson & 1994 \\
\hline 64 & The Small Vases from Hebron & Naomi Shihab Nye & 1998 \\
\hline 65 & Hello & Naomi Shihab Nye & 1995 \\
\hline 66 & Personal Poem & Frank O'Hara & 1964 \\
\hline 67 & Why I Am Not A Painter & Frank O'Hara & 1966 \\
\hline 68 & May-68 & Sharon Olds & 1996 \\
\hline 69 & University Hospital Boston & Mary Oliver & 1983 \\
\hline 70 & The Summer Day & Mary Oliver & 1992 \\
\hline 71 & Dearest Reader & Michael Palmer & 1984 \\
\hline 72 & Aubade: Some Peaches After Storm & Carl Phillips & 2004 \\
\hline 73 & Crossing The Water & Sylvia Plath & 1971 \\
\hline 74 & Power & Adrienne Rich & 1974 \\
\hline 75 & Root Cellar & Theodore Roethke & 1948 \\
\hline 76 & The Room of My Life & Anne Sexton & 1981 \\
\hline 77 & Her Kind & Anne Sexton & 1981 \\
\hline 78 & Fork & Charles Simic & 1999 \\
\hline 79 & My Noiseless Entourage & Charles Simic & 2005 \\
\hline 80 & Working Late & Louis Simpson & 1988 \\
\hline 81 & Cleaning a Fish & Dave Smith & 1985 \\
\hline 82 & Pacemaker & W.D. Snodgrass & 2002 \\
\hline 83 & Hay for the Horses & Gary Synder & 1958 \\
\hline 84 & Oranges & Gary Soto & 1985 \\
\hline 85 & Glass-Bottom Boat & Elizabeth Spires & 1989 \\
\hline 86 & Gin & David St. John & 1994 \\
\hline 87 & Traveling through the Dark & William Stafford & 1998 \\
\hline 88 & Notice What This Poem Is Not Doing & William Stafford & 1953 \\
\hline 89 & The Dancing & Gerald Stern & 1982 \\
\hline 90 & The Prediction & Mark Strand & 1979 \\
\hline 91 & The Night The Porch & Mark Strand & 2009 \\
\hline 92 & Letter & Jean Valentine & 2004 \\
\hline 93 & Year's End & Ellen Bryant Voigt & 1983 \\
\hline 94 & In Trackless Woods & Richard Wilbur & 2003 \\
\hline 95 & The Singing & C. K. Williams & 2003 \\
\hline 96 & More Blues and the Abstract Truth & C.D. Write & 2002 \\
\hline 97 & Approximately Forever & C.D. Wright & 2002 \\
\hline 98 & Clear Night & Charles Wright & 1982 \\
\hline 99 & $\begin{array}{l}\text { Lying in a Hammock at William Duffy's Farm in Pine } \\
\text { Island Minnesota }\end{array}$ & James Wright & 1990 \\
\hline 100 & A Blessing & James Wright & 1990 \\
\hline
\end{tabular}




\section{Contemporary amateur}

100 poems taken from a website for Amateur Writing (http://www.amateurwriting.com). All poems are anonymous and have no publication date.

\begin{tabular}{|c|c|}
\hline No. & Poem title \\
\hline 1 & Only but a dream \\
\hline 2 & Dr. Heinz Doofenshmirtz \\
\hline 3 & Freedom \\
\hline 4 & The foolish man \\
\hline 5 & Live for the moment \\
\hline 6 & Eaten up \\
\hline 7 & Gates of Goodbye \\
\hline 8 & true beauty \\
\hline 9 & A Walk in the Park \\
\hline 10 & The two of them \\
\hline 11 & Your life \\
\hline 12 & Thing we have lost in fire \\
\hline 13 & Mother Rabbit \\
\hline 14 & Aurora \\
\hline 15 & Boy to a man \\
\hline 16 & Goodbye poem \\
\hline 17 & Read me \\
\hline 18 & Angel eyes \\
\hline 19 & Another Chapter \\
\hline 20 & Self Reserved \\
\hline 21 & Yet the sun still sleeps. \\
\hline 22 & Let love be as one \\
\hline 23 & Charlotte Emily and Anne \\
\hline 24 & Cappuccino \\
\hline 25 & Pleasure trip \\
\hline 26 & I thought I knew \\
\hline 27 & Where is our fate formed? \\
\hline 28 & Sometimes \\
\hline 29 & Life \\
\hline 30 & You can cry \\
\hline 31 & Breaking heart \\
\hline 32 & And a Merry Christmas to You \\
\hline 33 & Everybody likes my clock \\
\hline 34 & I nearly fell \\
\hline 35 & Denial \\
\hline 36 & Winter silence \\
\hline 37 & Demons and scars \\
\hline 38 & The first time I saw you. \\
\hline 39 & Sister \\
\hline 40 & For Thee \\
\hline 41 & Precious Lord \\
\hline 42 & Love is like \\
\hline 43 & Life2 \\
\hline 44 & To Be Young And Naive \\
\hline 45 & Why I love You \\
\hline 46 & First Love \\
\hline 47 & Miss You \\
\hline 48 & THE END HAD COME \\
\hline 49 & BABY OF POVERTY \\
\hline 50 & Broken Home \\
\hline
\end{tabular}

\begin{tabular}{ll}
\hline No. & Poem title \\
\hline 51 & My Thoughts On Love \\
52 & Take Me Back \\
53 & A Friend Is \\
54 & THE GARDEN \\
55 & Insomnia \\
56 & Unrequited Love \\
57 & Wavering \\
58 & Garden of Shattered Dreams \\
59 & Thinking Of You \\
60 & My heart bleeds \\
61 & Time Isn't Always a good thing \\
62 & Is It Really Love \\
63 & Same Ole' Story \\
64 & Restored \\
65 & Do You? \\
66 & Adoption is Love \\
67 & Road to Happiness \\
68 & Untitled 1 \\
69 & Reflection \\
70 & A DREAM WITHIN A DREAM \\
71 & Waiting \\
72 & The War \\
73 & On a Moonlit Night \\
74 & Traipsing on Bantayan Shore \\
75 & you are my angel \\
76 & I Know \\
77 & The Way That You Left Me \\
78 & Waiting for Love \\
79 & a love without good-byes \\
80 & Wail of a wave \\
81 & Your still here \\
82 & Why? \\
83 & Always on my mind. \\
84 & Lonely in the dark room \\
85 & Untitled 2 \\
86 & As One \\
87 & life goes on \\
88 & Everlasting Love \\
89 & ethics of the blacks \\
90 & Hazed Maze \\
91 & ME AND YOU \\
92 & When you left \\
93 & MAGIC \\
94 & TOGETHER. FOREVER! \\
95 & YOU ARE MY EVERYTHING \\
96 & Believe in Miracles! \\
97 & A Lie \\
98 & I love you \\
\hline 00 & Memories \\
\hline
\end{tabular}

